\title{
Vivendo a inovaçãa: as experiências no curso de nutrição
}

Maísa Beltrame Pedroso ${ }^{1}$

Maria Isabel da Cunha

PEDROSO, M.B.; CUNHA, M.I. Living innovation: experiences in the course of nutrition. Interface - Comunic., Saúde, Educ., v.12, n.24, p.141-52, jan./mar. 2008.

This study results from careful considerations on the pedagogical practices considered meaningful by students of the undergraduate course of Nutrition, as well as, in the protagonism of the female teachers who develop them. We tried to understand whether these experiences mean innovation in the perspective of a paradigmatic rupture, considering innovation as a discontinuous process of breakage with traditional ways of teaching and learning. A qualitative methodology of study and the ethnographic approach principles were used. The activities pointed out by the students as meaningful practice were of different kinds and included those interactions with affective and subjective dimensions, which involve emotion, sensitivity, and esthetic perception, articulating, thus, subjectivity and objectivity, science and culture, technique and politics. Personal and professional trajectories are defining factors of teachers' performances, revealing their conceptions on their pedagogical procedures. They indicate the conditions in the constitution of the higher education teacher professionality. So, this study aligns to other researches that aim at building the basis of the university pedagogy.

Key words: Universities. Teaching. Innovation. Higher education.
O texto decorre de reflexão sobre práticas pedagógicas consideradas significativas pelos estudantes do Curso de Nutrição, numa instituição de Ensino Superior, Rio Grande do Sul, e no protagonismo das professoras que as desenvolvem. Procurouse investigar se essas experiências significam inovação na perspectiva de uma ruptura paradigmática, compreendendo a inovação como um processo descontínuo, de ruptura com as formas tradicionais do ensinar $\mathrm{e}$ aprender. Utilizou-se a metodologia qualitativa de pesquisa e os princípios da abordagem etnográfica. As atividades elencadas pelos alunos como práticas significativas foram de diferentes naturezas, incluindo emoção, sensibilidade e percepção estética, e articulando subjetividade e objetividade, ciência e cultura, técnica e política. As trajetórias pessoais e profissionais são fatores definidores dos modos de atuação das professoras, revelando suas concepções sobre seu fazer pedagógico e indicam condições presentes na constituição da profissionalidade do docente da educação superior. Nessa direção, alinha-se a outros estudos que objetivam construir as bases de uma pedagogia universitária.

Palavras-chave: Universidades. Ensino. Inovação. Educação superior.

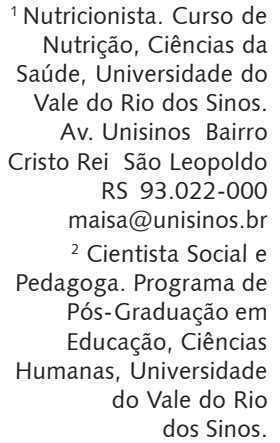


O mundo de minha vida diária não é $e_{\perp}$ de forma alguma ${ }_{\perp}$ meu mundo privado, mas é, desde o início, um mundo intersubjetivo compartilhado com meus semelhantes, vivenciado e interpretado por outros. (Wagner, 1979, p.159)

Ao longo de sua história, a universidade desempenhou as funções de depositária da cultura, agente social de manutenção da ordem, meio de adaptação às mudanças sociais e, ainda, de elaboração do conhecimento e construção do modelo cultural da sociedade. As atuais políticas nacionais de saúde e educação apontam para a necessidade de mudanças nos processos de formação profissional e têm estimulado e apoiado iniciativas no sentido da ampliação da responsabilidade social dos seus egressos. Rhors, citado por Sarmento (1992), discute as mudanças que a universidade terá de experimentar para continuar a enfrentar as exigências atuais. Para o autor, três são os elementos fundamentais para esse desafio: a idéia de autonomia, que representa liberdade e auto-suficiência da modalidade científica de existência; a busca da verdade, que se efetiva dentro da comunidade de docentes e discentes numa ação recíproca; e a unidade entre a investigação e o ensino, que necessita investimentos intencionais para a sua realização. Esses elementos prevêem uma ruptura epistemológica e ética como emergente.

Santos (2002) explicita que a cultura ocidental atravessa um momento de transição da modernidade para a pós-modernidade, criando um ambiente de incerteza e de caos, que repercute nas estruturas e práticas sociais, instituições e ideologias, representações sociais e inteligibilidades, na vida vivida e personalidade. Essa transição ocorre entre o paradigma da ciência moderna do conhecimento-regulação e o paradigma emergente, denominado, pelo autor, de "paradigma do conhecimento prudente para uma vida decente" (p.74). O conhecimento-emancipação e societal, menos visível, coteja o paradigma dominante e constitui-se num novo paradigma que permite reinventar os caminhos do inconformismo contra toda forma de naturalização da opressão. Santos (2002) afirma que o "único caminho para pensar o futuro parece ser a utopia. E por utopia entendo a exploração, através da imaginação, de novas possibilidades humanas e novas formas de vontade" (p.331-2).

As transformações vividas pela universidade apresentam uma série de perspectivas que estimulam a compreensão histórica e crítica de suas manifestações nos âmbitos epistemológico e político. $\mathrm{Na}$ visão de Rozendo et al. (1999), a educação superior, de maneira geral, prioriza práticas pedagógicas que, muitas vezes, não contribuem para o desenvolvimento de uma sociedade de sujeitos sociais construtores de sua própria história. Para os autores, a concepção predominante é a de uma educação para o ajustamento, para a adaptação a normas e padrões de comportamento considerados adequados, em que é imposta aos educandos, não raramente, uma condição de passividade e subordinação à autoridade do educador. Portanto, a prática educacional continua enraizada na concepção bancária de educação (Freire, 1979). Entretanto, se a concepção tradicional de ensinar e aprender é corrente na universidade, também aí se localizam espaços para transformação, porque nela existem homens, e porque são concretizadas ações realizadas por homens e a eles destinadas, as quais destinam-se ao desenvolvimento da consciência crítica sobre a realidade. Na opinião de Rozendo et al. (1999, p.16),

a universidade, enquanto uma instituição social inserida numa realidade concreta, experimenta a dialética do movimento social. Ao mesmo tempo em que determina, é determinada; ao mesmo tempo em que transforma a realidade, também reproduz esta realidade. Compartilha as contradições da sociedade e produz suas próprias contradições.

Assmann (2004) também contribui afirmando que a concepção de conhecimento abarca todos os processos naturais e sociais próprios do contexto onde são gerados e, a partir daí, esses processos 
${ }^{3}$ Conceito oriundo da área musical e que bem define a proposta de Assmann. "É a arte dos DJs de passar de uma música para outra sem que caia o ritmo da pista de dança. Quando perfeita, os alegres dançarinos nem percebem que já mudou de música". Disponível em: <www.terra.com. $\mathrm{br} / \mathrm{mp} 3 \mathrm{box} / \mathrm{col}$ pecanha4.html >. Acesso em: 17 ago. 2005. indicam formas de aprendizagem. Nessa perspectiva, a experiência de aprendizagem implica, além da instrução informativa, a reinvenção e a construção personalizada do conhecimento. Com essa possibilidade, a dimensão do prazer representa uma condição-chave, que envolve a subjetividade dos sujeitos implicados e proporciona o encantamento. Para o autor, "reencantar a educação significa colocar ênfase numa visão da ação educativa como ensejamento e produção de experiências de aprendizagem" (Assmann, 2004, p.29). Reforça, ainda, que o ambiente pedagógico tem de ser um lugar de fascinação e inventividade, para que o processo de aprender aconteça como mixagem ${ }^{3}$ de todos os sentidos, potencializando-os e (re)significando os modos como concebemos o mundo. É preciso (re) introduzir na escola o princípio de que toda a morfogênese do conhecimento tem algo a ver com a experiência do prazer, pois, na sua concepção, o conhecimento só emerge em sua dimensão vitalizadora quando é construído com esse pressuposto.

Ao estudarmos as práticas educativas, não podemos negar que toda a educação tem caráter político, mas devemos, sim,

$$
\begin{aligned}
& \text { entender que o ético-político se enraíza em campos do sentido, que } \\
& \text { emergem sob a forma de experiências de aprendizagem, que por sua } \\
& \text { vez emergem de processos auto-organizativos da vida real, onde viver } \\
& \text { e aprender se identificam num único processo. (Assmann, 2004, p.108) }
\end{aligned}
$$

As práticas pedagógicas realizadas no interior da sala de aula universitária são reflexos da sociedade e nela se refletem, espelhando a complexidade da dinâmica social e da interação humana. Conhecer tais práticas e desvelá-las é fundamental para compreendê-las, oferecendo subsídios aos professores universitários, para analisar os momentos de transição paradigmática em que vivem. Rever a formação do professor universitário em face das mudanças de paradigma é repensar a inovação no sentido de compreender as atividades de ensino, pesquisa e aprendizagem em constante movimento, desenvolvendo-se ao longo da história, instigando e propiciando a descoberta e a aprendizagem do aluno por meio da relação dialógica com o professor.

Nessa perspectiva, buscou-se identificar e caracterizar as práticas pedagógicas dos docentes de um Curso de Graduação em Nutrição, que apresentavam indícios de aprendizagens emancipatórias, realizando uma reflexão sobre o caráter inovador dessas práticas, entendidas como aquelas que favorecem a ruptura com as formas tradicionais de ensinar e aprender. Os caminhos metodológicos adotados envolveram o diálogo com a literatura e registros realizados com base em entrevistas com os professores identificados por seus alunos como sendo aqueles que protagonizaram experiências de ensinar e aprender que foram significativas em suas trajetórias acadêmicas. Relacionar as aprendizagens significativas com a possibilidade da inovação foi outro intento assumido no contexto do estudo. Para tanto, dialogando com os autores escolhidos, procuramos identificar características nas experiências, tais como: - estar em movimento constante, instigando e propiciando o descobrimento do novo; - trabalhar com as múltiplas tensões presentes nas atividades dos alunos; - favorecer a relação horizontal professor-aluno, permitindo atendimento à singularidade de cada um, evitando a homogeneização; - assegurar a relação ensino-pesquisa, tendo o trabalho como princípio educativo; - constituir-se como atividades coletivas permeadas por intencionalidade; - atribuir à pesquisa destacado espaço de mediação entre o ensinar e o aprender. 
Essas características, assumidas como ponto de partida da pesquisa, aproximaram-se das categorias organizadas por Cunha $(2004,1998)$ em outros estudos e que foram tomadas como referentes para a análise dos dados, com a intenção de contribuir para a consolidação teórica dos pressupostos analíticos dos estudos sobre inovação. São elas:

- ruptura com a forma tradicional de ensinar e aprender e/ou com os procedimentos acadêmicos inspirados nos princípios positivistas da ciência moderna;

- gestão participativa, por meio da qual os sujeitos do processo inovador são protagonistas da experiência, desde a concepção até a análise dos resultados;

- reconfiguração de saberes, com a anulação ou diminuição das clássicas dualidades entre saber científico/saber popular, ciência/cultura, educação/trabalho etc;

- reorganização da relação teoria/prática, rompendo com a clássica proposição de que a teoria precede a prática, dicotomizando a visão de totalidade;

- perspectiva orgânica no processo de concepção, desenvolvimento e avaliação da experiência desenvolvida;

- mediação entre as subjetividades dos envolvidos e o conhecimento, englobando a dimensão das relações e do gosto, do respeito mútuo, dos laços que se estabelecem entre os sujeitos e o que se propõem conhecer;

- protagonismo, compreendido como a participação dos alunos nas decisões pedagógicas, valorização da produção pessoal, original e criativa dos estudantes, estimulando processos intelectuais mais complexos e não repetitivos.

Essas categorias explicitam a compreensão de que a inovação pressupõe alterações na concepção de conhecimento presidido pela ciência moderna. Portanto, não se referem somente a arranjos metodológicos ou inclusão de aparatos tecnológicos. Incorporam, necessariamente, uma nova epistemologia que se traduz nas práticas de sala de aula.

\section{Conhecendo as experiências que anunciam a inovação}

Descrevemos, a seguir, cada situação de ensino-aprendizagem que compõe este estudo com base no relato das professoras. Procuramos identificar nelas as categorias teóricas que orientaram a pesquisa. As experiências estão relatadas na mesma seqüência das entrevistas realizadas.

\section{Experiência I}

\section{A construção progressiva da identidade profissional}

Trata-se de uma experiência na disciplina de Estágio III, que se caracteriza por ser a última etapa necessária para a conclusão do curso de Nutrição. A professora trabalha com um grupo de, aproximadamente, 15 alunos, que realizam seus estágios em diferentes hospitais. Os alunos desenvolvem suas atividades, interagindo com a rotina do hospital, realizando visitas aos leitos, fazendo avaliação nutricional, acompanhando a evolução dos pacientes e realizando as intervenções necessárias. Todas as atividades são supervisionadas pelos nutricionistas dos locais. Os alunos, quando o local permite, participam de reuniões de discussão com grupos multidisciplinares.

A professora realiza a supervisão acadêmica, em encontros semanais, na Universidade. Nesses encontros, os alunos relatam suas experiências, tiram suas dúvidas e discutem os procedimentos nutricionais. Cabe à professora acompanhar os relatos dos casos reais, oportunizando uma avaliação crítica sobre os procedimentos adotados e incentivando a busca de artigos atuais sobre o assunto. Leva em consideração que os locais que recebem os alunos para estágio nem sempre apresentam as condições ideais na prestação de serviços de saúde. O papel da professora é desafiar o aluno a desenvolver seu potencial, mobilizando conhecimentos para o desenvolvimento de situações concretas de aprendizagem. Para a professora, o aluno tem "que tentar fazer a diferença, apresentar propostas diferenciadas, valorizando o atendimento personalizado, pois nenhum paciente é igual ao outro". 
$\mathrm{Na}$ visão da professora, a atividade desafia para o novo e possibilita ao aluno se exercitar no papel de nutricionista. Ao descrever a atividade, relata: "Eu incentivo que o aluno desenvolva seu potencial de nutricionista da área clínica um pouco mais independente daquela rotina que o local tem. Eu desafio o aluno e digo: você tem de tentar fazer a diferença". Continua sua narrativa dizendo

acredito que assim o aluno se testa. Ele nem pensava que poderia ir tão longe. Ele começa a perceber que nem sempre a referência maior é a equipe do local e vai descobrir outras referências, vai descobrir a bibliografia, vai descobrir os novos artigos científicos daquela patologia. E pode somar essas referências com as que a equipe tem. E se descobre como alguém que desconhecia [...] como alguém capaz de saber além do que era solicitado.

O educando é o ator principal no processo de seu desenvolvimento. Por meio desse tipo de ação, adquire e amplia seu repertório interativo, aumentando, assim, sua capacidade de interferir de forma ativa e construtiva em seu contexto. A centralidade da proposta incide na participação ativa, construtiva e solidária, em que o aluno envolve-se na solução de problemas reais na universidade, na comunidade e na sociedade.

\section{Experiência II}

\section{Trilhando os caminhos da pesquisa}

Trata-se de uma experiência realizada na disciplina de Seminário II. Essa disciplina aborda temas ligados aos assuntos que permeiam o Eixo II - Nutrição e Desenvolvimento Humano, e objetiva trabalhar, de maneira sistêmica, os conteúdos referentes às disciplinas que pertencem ao eixo comum. Pretende, ainda, que os alunos integrem os conhecimentos, desfazendo a relação fragmentada de conteúdos. Propõe que eles realizem discussões mais ampliadas sobre determinados assuntos, permitindo perspectivas interativas de campos disciplinares, além de revisão e suprimento de eventuais temas. Essa disciplina não tem o conteúdo programático totalmente preestabelecido. Este é escolhido no início de cada semestre com base em uma avaliação realizada pela professora com os seus estudantes, desde que contemple questões da atualidade. O planejamento das atividades é elaborado a cada semestre e tem como referente a ementa oficial, conhecida por todos os alunos. A professora propõe estratégias, valendo-se de discussões com eles. Dessa forma, oportuniza que façam interações e atualizações de seus conhecimentos no campo da Nutrição e áreas afins. A turma, de aproximadamente trinta alunos, é dividida em grupos. Cada grupo fica responsável pela apresentação de um tema, usando os princípios da técnica de Seminário. A dinâmica deve levar em conta a pluralidade dos participantes. Os seminários são acompanhados pelo professor, que atua como um articulador.

No início do semestre, a professora trabalha a preparação do seminário, mostrando como se faz uma pesquisa bibliográfica, seus passos, cuidados e pressupostos. Leva os alunos até a biblioteca e ensina como se realiza a busca na Internet. Mostra seus cantos preferidos da biblioteca, incentivando seus alunos a manipularem os periódicos principais, destacando a importância destes no contexto científico. Faz com que cada aluno leia um periódico internacional, estimulando a leitura em outra língua e mostrando como é possível realizar essa atividade. Na apresentação dos seminários, é destacada a atualização do assunto, bem como o referencial bibliográfico que the dá sustentação. Vale ressaltar que toda a produção dos demais alunos é discutida na presença daquele que foi o autor. $O$ erro é tratado como fator de diagnóstico, provocando as intervenções do professor e dos colegas.

$\mathrm{Na}$ apresentação dos trabalhos, a professora sempre complementa os assuntos, destacando como sãos conectados com a prática profissional. "Eu sempre complementei muito com a minha experiência, então, em cada seminário, os alunos pareciam aprender muito. Em todo tema, eu contava um caso, eu contava uma história".

Nessa experiência, a avaliação é realizada por meio de múltiplos procedimentos, incluindo uma prova, onde são cobrados os conhecimentos trabalhados em sala de aula, bem como as discussões 
que eles suscitaram. Também são avaliados os procedimentos processuais e o envolvimento dos estudantes com a proposta.

As atividades de pesquisa desenvolvidas pela professora repercutem em seu trabalho na sala de aula. Na percepção da professora, a experiência é significativa para o aluno porque seu nome está ligado ao desenvolvimento de pesquisas.

Criei uma cultura de desenvolvimento de pesquisa desde que aqui cheguei, em agosto de 2001. E, em outubro, já estava com os alunos, indo para o Hospital Centenário, selecionando as crianças. A cada curto espaço de tempo, estava promovendo trabalhos, e os alunos comentavam: "Eu estou fazendo um trabalho com a professora Márcia, estou coletando dados. Isso provavelmente foi gerando toda uma cultura em volta do meu nome [...]".

Esse é um processo interessante porque integra ensino e pesquisa e dá sentido à produção de conhecimento, que é tarefa da universidade. Integra o espaço de graduação com a pesquisa, assumindo essa condição como possibilidade de qualificar o processo de ensinar e aprender.

\section{Experiência III}

\section{A teoria em prática}

Trata-se de uma experiência de Estágio II, disciplina do Eixo Nutrição e Desenvolvimento Humano, realizada no Hospital Materno-Infantil. É um hospital da rede pública, onde a professora é referência para o aluno, pois foi lá também que desenvolveu suas atividades profissionais, proporcionando sustentação ao referencial teórico apresentado em sala de aula e inserindo o aluno no campo profissional. Os alunos realizam visitas ao leito das pacientes internadas, que são parturientes, avaliando o prontuário para conhecimento da situação em que se encontram. Acompanham a primeira mamada dos recém-nascidos e incentivam as mães para a prática do aleitamento. Realizam processos demonstrativos de como, por exemplo, a mãe deve colocar o bebê ao seio, ajudando no esgotamento da mama. Acompanham e observam as reações das pacientes e procuram intervir nas práticas culturais do aleitamento, na perspectiva de aperfeiçoá-las. Os alunos que optam por realizar seu estágio nesse local vivenciam a prática de saúde pública, junto ao hospital que é referência no atendimento à gestante. A professora também é responsável pela disciplina Nutrição dos Ciclos da Vida I, e já desenvolveu, com os alunos, os pressupostos que são objetos do estágio, incluindo os aspectos relacionados à gestação e ao primeiro ano de vida da criança. Na visão da professora, essa relação prévia que tem com seus alunos favorece a aprendizagem, o que pode ser percebido com base em seu depoimento.

Acho que eu, particularmente, por trabalhar no Ciclo, faço o gancho com o HPV, onde faço a supervisão de estágio. Tem tudo a ver, pois dá para juntar a questão de sala de aula com a questão prática. Acho que os alunos vêem a evolução da aprendizagem, efetivando aquilo que viram em sala de aula. Eles podem ver, na prática, o que se discutiu em sala de aula. Acho que isso dá uma certa satisfação.

Essa experiência proporciona uma postura proativa do aluno, pois favorece o estabelecimento de relações entre o novo, que está sendo vivenciado no estágio, e os conhecimentos já presentes em sua estrutura cognitiva, permitindo o estabelecimento de redes e relações de diferentes matizes de extensão e complexidade. Nessa experiência, os alunos também são protagonistas da construção de seu conhecimento quando são chamados a participar de grupos operativos com as nutrizes e toda a equipe de profissionais, médicos, enfermeiros, psicólogos etc., favorecendo a relação interpessoal e os processos de comunicação do aluno e suas pacientes; do professor e os alunos; dos alunos entre si, e do aluno com os profissionais da área. 


\section{Experiência IV}

\section{O professor como facilitador da aprendizagem}

A disciplina em questão está localizada no segundo semestre do curso. A professora, no primeiro dia de aula, faz a caracterização da disciplina, descrevendo os tópicos que serão trabalhados durante o semestre, retomando os conteúdos que foram dados na disciplina que a antecedeu. Essa disciplina estuda as alterações físico-químicas e biológicas dos alimentos. Na primeira aula, a professora procura fazer com que o aluno entenda a importância do conhecimento da composição química dos alimentos, como esta pode sofrer alterações, de que forma isso ocorre no fazer diário, e o uso dessas propriedades na atividade prática do profissional nutricionista, favorecendo uma visão da trajetória acadêmica que o aluno deve percorrer. A professora toma, como referente da sua proposta, a escolha de um alimento que possa sustentar a exposição do conteúdo. "Penso em um alimento e tento esgotar esse alimento, indo desde o início, que é a composição química, até o final, que é a sua utilização". É feita uma explanação teórica sobre o mesmo e, após, os alunos exercitam o que aprenderam por meio das preparações no laboratório de Nutrição e Dietética. Formam-se grupos de quatro a cinco alunos, e cada grupo assume uma das cozinhas experimentais onde as preparações devem ser executadas. Ao final do período, cada grupo apresenta as preparações feitas para o grande grupo, descrevendo o processo e as alterações propostas. Após a degustação, são realizadas as avaliações de cada preparação. No momento da explanação, a professora vai questionando os conhecimentos e chamando a atenção para as alterações sofridas pelos alimentos e para a sua utilização na prática do profissional nutricionista. Há a intenção de tomar as informações da vida cotidiana como ponto de partida para a reflexão teórica. Explica a professora:

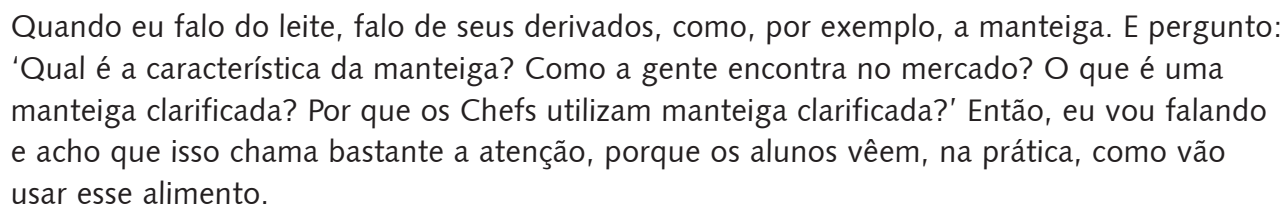

De acordo com a professora, não existe um cronograma fixo a ser seguido. As escolhas dos conteúdos a serem desenvolvidos nas aulas se dão pelo interesse despertado nos alunos em sala de aula, ou mesmo pelas curiosidades estimuladas pela professora para que os alunos aprofundem seu conhecimento sobre o alimento, extrapolando o mínimo exigido pela disciplina. No entanto, é importante destacar que há um roteiro de conteúdos importantes a serem trabalhados, que não é fixo, mas, ao final do semestre, todos são cumpridos.

\section{Refletindo sobre as experiências que anunciam a inovação}

Os alunos, ao elegerem as experiências significativas, evidenciavam a importância dada ao movimento entre a teoria e a prática como referência do trabalho acadêmico. Essa categoria, que emerge no depoimento dos estudantes, é recuperada pelos professores quando descrevem as suas práticas. As experiências citadas pelos alunos são portadoras de situações de ensino que desenvolvem o eixo teoria-prática em atividades inovadoras, permitindo, às vezes, diferenciar categorias que incluem atividades com significado diferenciado. Verifica-se a importância dos trabalhos desenvolvidos nos campos de estágios, em atividades realizadas em laboratórios e em visitas a bibliotecas. Destaca-se o trabalho em equipe e as reflexões para sistematização dos estudos. Em todas essas instâncias, o que o aluno valoriza tem sido a condição de produzir conhecimento por meio da investigação e de ser protagonista de uma ação que tem a realidade como referencial.

O espaço de formação não ocorre somente nos bancos acadêmicos. A formação se dá em múltiplos espaços, assim como são múltiplas as aprendizagens que acontecem em cada um desses espaços. Para os professores entrevistados, a atividade prática que ocorre em territórios não- 
convencionais é o elemento de partida para aquisição de conhecimentos. Possibilitam ao aluno uma atitude mais reflexiva e ativa diante dos novos saberes, permitindo que se estabeleçam relações entre a realidade e a fundamentação teórica, propiciando, dessa forma, uma reconfiguração de saberes. Para esses professores, a concepção de conhecimento deve envolver flexibilidade e movimento, ocorrendo uma significativa valorização das experiências profissionais como forma de permitir uma articulação entre teoria e prática, como podemos observar nos relatos a seguir.

No meu ponto de vista, toda atividade vivencial tem uma importância significativa. Acho que a prática e a vivência são fundamentais para desencadear todo um processo de conhecimento humano.

Ou:

eu acho que na disciplina [...] tem de se repensar para trazer, junto com a teoria, a atividade prática. Ainda não estou conseguindo fazer. Eu creio que poderia trabalhar melhor o recémnascido, se os alunos pudessem ver não só no slide, mas como é na realidade. E é isso o que eles vêem no Estágio II.

Essa concepção também é partilhada por Lucarelli (2005), para quem a articulação teoria-prática se constitui no eixo central dinamizador das inovações didático-curriculares na aula universitária, sendo uma das possibilidades de transformação do ensino nas universidades. Para a autora,

dada la importancia que asumen en la institución las definiciones acerca de la naturaleza del conocimiento tanto en lo relativo a su producción como en lo referente a los procesos y contenidos en la formación de los sujetos; a la vez, esa articulación se hace presente en el contexto universitario a través de la inclusión de la profesión, sus representaciones y sus prácticas, como anticipatorios del campo laboral en el que desarrollará su actividad el egresado. (Lucarelli, 2005, s/p)

Essa questão permite analisar a articulação entre a teoria e a prática na perspectiva de um entrelaçamento de aspectos epistemológicos e didáticos, o qual aponta para novos enfoques acerca dos processos de formação profissional. Lucarelli lembra que esta nova epistemologia supõe que a articulação da teoria e da prática se desenvolva por meio de uma estratégia metodológica em que se propicia a reflexão na ação, proporcionando uma reflexão sobre o que está se fazendo simultaneamente ao momento da ação. Argumenta, ainda, que

en el caso de la formación en la práctica profesional, el conocimiento en la acción propio de cada campo adquiere las características que le otorga el contexto estructurado, social e institucional, de esa profesión. Conocimiento profesional y sistema de valores compartido definen un determinado campo profesional y generan las formas del conocimiento en acción, a la vez que la concepción epistemológica acerca de la práctica profesional determina la estrategia general de formación. (Lucarelli, 2005, s/p)

Nesse caso se justifica a valorização da experiência como meio possível de articulação entre teoria-prática na formação profissional, como afirmam os entrevistados: "No Estágio II, os alunos têm a oportunidade de exercitar o que foi trabalhado em sala de aula". E, ainda,

vou mostrando como vai acontecer no decorrer do Curso. Qual é a importância do alimento, quando vai se fazer a preparação? E, depois, que repercussões teremos na dietoterapia? Pergunto sempre: "Na dietoterapia, tem importância esse alimento? Como eu vou usá-lo? Eu vou poder colocá-lo em qualquer dieta?" 
Na visão das professoras, os alunos desenvolvem, nesse exercício, sua autonomia e capacidade de análise, refletindo sobre o processo como um todo e conseguindo avaliar a utilização do conhecimento na prática profissional. Eles são estimulados a buscar novos conhecimentos, quando são interpelados por perguntas que suscitam a curiosidade e a necessidade de avançar no conhecimento. Os conteúdos passam a ser explorados considerando o significado a eles atribuídos e sua consistência e funcionalidade para o enfrentamento de situações reais. A construção de significados ultrapassa uma aprendizagem baseada na memória e apela para uma aprendizagem que tem, como pressuposto, a integração teoria-prática.

É possível perceber que as experiências se identificam com o conceito aqui adotado para inovação, na medida em que estimulam os alunos a realizar uma leitura do campo profissional, exigindo uma reconfiguração epistemológica. O conceito de conhecimento é compreendido sob outras bases, afastando-se da tradicional formulação da ciência moderna, prescritiva, generalizadora e compartimentada. Procura-se um conhecimento percebido como processo, sempre em movimento, favorecendo a ruptura com a visão de ensino tradicional. Podemos perceber, também, que as professoras reconhecem que há formas e fontes alternativas de produção de conhecimento. "Então eu digo para eles: 'Proponham, façam as suas propostas. Se você fosse o nutricionista deste local como é que faria a atenção a esses pacientes?' E, assim, eu os desafio o tempo todo, no estágio".

As professoras parecem ampliar as dimensões da aprendizagem, destacando as repercussões das experiências prévias sobre a assimilação do conhecimento novo e ressaltando duas condições para a (re) construção de significado: um conteúdo potencialmente significativo e uma atitude favorável para aprender significativamente, o que confirma o pensamento de Lima (2005, p.374), para quem

uma aprendizagem significativa requer do aprendiz uma postura proativa que favoreça o estabelecimento de relações entre o novo e os elementos já presentes em sua estrutura cognitiva.

Nas experiências relatadas, percebem-se as condições para a ruptura quando as docentes possibilitam a organização de ambientes de aprendizagem que sejam mediadores dos processos de apropriação, discussão, análise e produção de conhecimento. As atividades, ao possibilitarem que os alunos alcancem um outro nível de apropriação do conhecimento, ao assumirem novos significados e ao propiciarem inter-relações com o cotidiano, em diferentes espaços sociais, evidenciam a configuração de movimentos de reflexão, crítica e proposições de caminhos.

No processo de investigação, encontramos também indicadores para o redimensionamento da forma tradicional de se trabalhar o erro, como afirmou uma das interlocutoras.

Fico ouvindo até o final, mesmo que os alunos estejam apresentando um trabalho aquém do esperado. Depois, no grande grupo, eu pontuo algumas manifestações, sobre algumas observações. Então, às vezes, eu constato que, há um grupo que não alcançou os objetivos, ou que ficou aquém do esperado. Eu não preciso dizer isso. Eles concluem no grande grupo e se manifestam, dizendo "podemos tentar mais uma vez? Nós vamos tentar agora em outro local!"

Percebe-se que, nessa perspectiva, o erro passou a fazer parte do processo ensino-aprendizagem, porque é trabalhado como parte da construção do conhecimento. Essa condição distensiona o aluno, liberando-o para novas aventuras epistemológicas. Nesse sentido, a relação pedagógica não é percebida como um campo para homogeneização, que oculta diferenças sociais, conflitos e contradições, mas como um campo de identidade e diversidade.

Investigar os processos de ensinar e aprender que se realizam no Curso de Nutrição fez-nos compreender que a forma como se transmite o conhecimento pode ter mais significado do que 0 próprio conhecimento. Em estudos anteriores, inspirados em Bernstein, afirmamos que 
não são os conteúdos ou as informações que carregam as relações sociais que geram a reprodução social ou cultural, mas a forma de transmissão, entendida como a teia de relações de poder e de subjetividade que as permeiam. (Cunha, 2001, p.105)

Foi possível perceber que as atividades consideradas pelos alunos como significativas na sua formação, independente do lugar em que aconteceram e dos objetivos estabelecidos no desenho da estrutura curricular, concretizam-se metodologicamente nas ações de ensino-aprendizagem que ocorrem na sala de aula, afetando, assim, de alguma maneira, a articulação teoria-prática, considerada processo genuíno de ensino-aprendizagem, revelando que os elementos que constituem a prática cotidiana incluem, mesmo que instintivamente, a dimensão do prazer. Todas elas mencionam a satisfação e a gratificação que está presente em suas docências. Essa condição reforça a perspectiva de Rios (2002), para quem a qualidade em educação se dá quando se faz bem nossa missão e quando ela também faz bem a nós.

A pesquisa que desenvolvemos reafirma a importância de se compreender e desenvolver conhecimentos sobre as práticas docentes que se instituem na Universidade. Importante, também, é que os professores reflitam sobre elas e que as alternativas de avanços surjam de suas reais possibilidades. Para Zabalza (2004, p.125), "refletir não é retornar constantemente aos assuntos utilizando os mesmos argumentos; é documentar a própria atuação, avaliá-la e implementar os processos de ajustes convenientes".

Desse modo, este estudo também buscou contribuir para a reflexão do que vem sendo realizado, analisando as articulações entre o projeto político-pedagógico do curso de Nutrição e as inovações que ocorrem na sala de aula, considerando que seu valor educativo reside na flexibilidade e contextualização dos atos de ensinar e aprender. Com ele foi possível constatar que vivemos a chamada fase de transição de paradigmas, com todas as tensões e desafios que ela impõe.

Percebemos que, como a inovação tem sempre um componente coletivo, é por meio da socialização das experiências significativas para os alunos, as quais resultam de práticas inovadoras dos professores, que poderemos ampliar as condições para a necessária ruptura paradigmática. Os professores que já estão produzindo inovações podem inspirar a renovação pedagógica para que essa se amplie, bem como mostrar que é possível estabelecer novas relações entre professor, aluno e conhecimento. Deste modo, compartilhamos os êxitos e dificuldades dos docentes na busca de uma prática que avance continuamente, incluindo os métodos, objetivos e conteúdos do Curso e modificando a práxis do ensinar e aprender, estimulando o prazer de estudar, de descobrir e de ser plenamente cidadão.

Reafirmamos, ainda, a importância da produção de conhecimento sobre a pedagogia universitária, numa intersecção de saberes que incluem a área de educação e o campo científico e profissional de carreiras acadêmicas. Parece que é com o diálogo epistemológico que se poderá fazer avançar o conhecimento e a profissionalização do professor universitário. Esse esforço exige humildade, capacidade de diálogo e requer objetivos comuns. 


\section{Referências}

ASSMANN, H. Reencantar a educação: rumo à sociedade aprendente. 8.ed. Petrópolis: Vozes, 2004.

CUNHA, M. I. Diferentes olhares sobre as práticas pedagógicas no ensino superior: a docência e sua formação. Educação (Porto Alegre), v.54, n.3, p.525-36, 2004.

Aprendizagens significativas na formação inicial de professores: um estudo no espaço dos Cursos de Licenciatura. Interface - Comunic., Saúde, Educ., v.5, n.9, p.103-16, 2001.

O professor universitário na transição de paradigmas. Araraquara: JM, 1998.

FREIRE, P. Pedagogia do oprimido. Rio de Janeiro: Paz e Terra, 1979.

LIMA, V.V. Competência: distintas abordagens e implicações na formação de profissionais de saúde. Interface - Comunic., Saúde, Educ., v.9, n.17, p.369-79, 2005.

LUCARELLI, E. Prácticas profesionales emergentes: un caso de innovación en la enseñanza universitaria. In: REUNIÃO ANUAL DA ANPED, 28., 2005, Caxambu. Anais... Caxambu, 2005. p.20. (mimegr.)

RIOS, T.A. Compreender e ensinar: por uma docência da melhor qualidade. 3.ed. São Paulo: Cortez, 2002.

ROZENDO, C.A. et al. Uma análise das práticas docentes de professores universitários da área de saúde. Rev. Latinoam. Enferm., v.7, n.2, p.15-23, 1999.

SANTOS, B.S. A crítica da razão indolente: contra o desperdício da experiência. 4.ed. São Paulo: Cortez, 2002.

SARMENTO, D.C. Núcleos interdisciplinares: seu potencial de dinamização da estrutura universitária. Educ. Bras., v.19, n.29, p.45-58, 1992.

WAGNER, H.R. Fenomenologia e relações sociais. Rio de Janeiro: Zahar, 1979.

ZABALZA, M.A. O ensino universitário: seu cenário e seus protagonistas. Porto Alegre: Artmed, 2004. 
PEDROSO, M.B.; CUNHA, M.I. Viviendo la innovación: experiencias en el título de licenciado/a en nutrición. Interface - Comunic., Saúde, Educ., v.12, n.24, p.141-52, jan./mar. 2008.

Este trabajo es el fruto de una reflexión docente sobre las prácticas pedagógicas, consideradas significativas por los estudiantes del título de Licenciado/a en Nutrición, pertenecientes a una Universidad de Río Grande do Sul (Brasil), desde el protagonismo de las Profesoras que lo han llevado a cabo. Pretendemos conocer si tales experiencias se traducen en innovaciones, desde una perspectiva de ruptura paradigmática, entendiendo la innovación como un proceso discontinuo de revolución ante las formas tradicionales de enseñar y aprender. Hemos utilizado una metodología de investigación de corte cualitativo, con los principios de abordaje etnográfico. La naturaleza de las actividades enunciadas por los estudiantes como prácticas significativas son diferentes, e incluyen la emoción, sensibilidad y percepción estética, articulando subjetividad y objetividad, ciencia y cultura, técnica y política. Las trayectorias personales y profesionales, son factores determinantes en el modo de actuación de las profesoras revelando sus concepciones sobre su quehacer pedagógico. Indican condiciones presentes en la constitución de la profesionalidad docente de la enseñanza superior. En esa dirección concuerdan con otros estudios que persiguen construir las bases de una pedagogía universitaria.

Palabras clave: Universidades. Enseñanza. Innovaciones. Educación superior. 